\title{
Inflammatory bowel disease: A Canadian burden of illness review
}

\author{
Angela Rocchi $\mathrm{MSc}^{1}$, Eric I Benchimol MD PhD², Charles N Bernstein $\mathrm{MD}^{3}$, Alain Bitton $\mathrm{MD}^{4}$, Brian Feagan $\mathrm{MD}^{5}$, \\ Remo Panaccione $\mathrm{MD}^{6}$, Kevin W Glasgow $\mathrm{MD}^{7}$, Aida Fernandes MBA7, Subrata Ghosh $\mathrm{MD}^{6}$
}

\begin{abstract}
A Rocchi, EI Benchimol, CN Bernstein, et al. Inflammatory bowel disease: A Canadian burden of illness review. Can J Gastroenterol 2012;26(11):811-818.
\end{abstract}

BACKGROUND: Inflammatory bowel diseases (IBD) - Crohn's disease (CD) and ulcerative colitis (UC) - significantly impact quality of life and account for substantial costs to the health care system and society. OBJECTIVE: To conduct a comprehensive review and summary of the burden of IBD that encompasses the epidemiology, direct medical costs, indirect costs and humanistic impact of these diseases in Canada.

METHODS: A literature search focused on Canadian data sources. Analyses were applied to the current 2012 Canadian population.

RESULTS: There are approximately 233,000 Canadians living with IBD in 2012 (129,000 individuals with CD and 104,000 with UC), corresponding to a prevalence of $0.67 \%$. Approximately 10,200 incident cases occur annually. IBD can be diagnosed at any age, with typical onset occurring in the second or third decade of life. There are approximately 5900 Canadian children $<18$ years of age with IBD. The economic costs of IBD are estimated to be $\$ 2.8$ billion in 2012 (almost $\$ 12,000$ per IBD patient). Direct medical costs exceed $\$ 1.2$ billion per annum and are driven by cost of medications ( $\$ 521$ million), hospitalizations (\$395 million) and physician visits (\$132 million). Indirect costs (society and patient costs) total $\$ 1.6$ billion and are dominated by long-term work losses of $\$ 979$ million. Compared with the general population, the quality of life patients experience is low across all dimensions of health.

CONCLUSIONS: The present review documents a high burden of illness from IBD due to its high prevalence in Canada combined with high per-patient costs. Canada has among the highest prevalence and incidence rates of IBD in the world. Individuals with IBD face challenges in the current environment including lack of awareness of IBD as a chronic disease, late or inappropriate diagnosis, inequitable access to health care services and expensive medications, diminished employment prospects and limited community-based support.

Key Words: Crohn's disease; Economic costs; Epidemiology; Inflammatory bowel disease; Quality of life; Ulcerative colitis

\section{Les maladies inflammatoires de l'intestin : une analyse du fardeau de la maladie au Canada}

HISTORIQUE : Les maladies inflammatoires de l'intestin (MII), soit la maladie de Crohn (MC) et la colite ulcéreuse (CU), ont des conséquences profondes sur la qualité de vie et coûtent très cher au système de santé et à la société.

OBJECTIF : Procéder à une analyse et un sommaire complets du fardeau des MII, qui englobent l'épidémiologie, les coûts médicaux directs, les coûts indirects et les répercussions humaines de ces maladies au Canada.

MÉTHODOLOGIE : Analyse bibliographique axée sur les sources de données canadiennes, appliquée à la population canadienne de 2012. RÉSULTATS : Environ 233000 Canadiens vivent avec une MII en 2012 (129000 personnes atteintes d'une MC et 104 000, d'une CU), soit une prévalence de 0,67\%. Environ 10200 nouveaux cas sont déclarés chaque année. Les MII peuvent être diagnostiquées à tout âge, mais elles font généralement leur apparition pendant la vingtaine ou la trentaine. Environ 5900 enfants canadiens de moins de 18 ans en sont atteints. On évalue leurs coûts économiques à 2,8 milliards de dollars en 2012 (près de $12000 \$$ par patient atteint). Les coûts médicaux directs dépassent les 1,2 milliard de dollars par année et sont attribuables au coût des médicaments (521 millions de dollars), des hospitalisations ( 345 millions de dollars) et des visites chez le médecin (132 millions de dollars). Les coûts indirects (coûts pour la société et pour les patients) totalisent 1,6 milliard de dollars et sont dominés par des pertes de productivité à long terme de 979 millions de dollars. Comparativement à la population générale, la qualité de vie des patients est faible dans toutes les dimensions de la santé.

CONCLUSIONS : La présente analyse étaye un fardeau élevé de maladie causé par les MII en raison de leur prévalence marquée au Canada et des coûts élevés par patient. Le Canada présente l'un des taux de prévalence et d'incidence les plus élevés de MII de par le monde. Les personnes atteintes d'une MII affrontent des défis dans l'environnement actuel, y compris le manque de sensibilisation au fait que les MII sont des maladies chroniques, le diagnostic tardif ou erroné, l'accès inéquitable aux services de santé et les médicaments coûteux, les perspectives d'emploi réduites et le soutien limité dans la collectivité.

incidence of both CD and UC are higher in families with a history of these diseases. To date, more than 160 gene alleles have been found to be associated with IBD.

In the absence of a cure, therapy is directed at quickly resolving symptoms during a flare and subsequently maintaining freedom from symptoms. Most individuals require medication; when drug therapy fails, surgery is often required. CD and UC are lifelong diseases, usually starting in early adulthood (and increasingly diagnosed in childhood) in otherwise healthy, active individuals. IBD significantly impacts quality of life in addition to a substantial personal burden through the gut. Genetics are believed to play an important role because the

${ }^{1}$ Axia Research, Burlington; ${ }^{2}$ Department of Epidemiology and Community Medicine, University of Ottawa, Ottawa, Ontario; ${ }^{3}$ Section of Gastroenterology, IBD Clinical and Research Centre, University of Manitoba, Winnipeg, Manitoba; ${ }^{4}$ Division of Gastroenterology, McGill University and McGill University Health Centre, Montreal, Quebec; ${ }^{5}$ Department of Epidemiology and Biostatisitcs, University of Western Ontario, London, Ontario; ${ }^{6}$ Department of Medicine, University of Calgary, Calgary, Alberta; ${ }^{7}$ Crohn's and Colitis Foundation of Canada, Toronto, Ontario

Correspondence and reprints: Ms Aida Fernandes, Crohn's and Colitis Foundation of Canada, 600-60 St Clair Avenue East, Toronto, Ontario M4T 1 N5.

Telephone 416-920-5035, fax 416-929-0364, e-mail afernandes@ccfc.ca

Received for publication September 4, 2012. Accepted September 9, 2012 


\section{TABLE 1}

\section{Steering Committee, 2012}

\begin{tabular}{l} 
Gastroenterologists \\
Eric I Benchimol MD PhD, University of Ottawa, Ottawa, Ontario \\
Charles N Bernstein MD, University of Manitoba, Winnipeg, Manitoba \\
Alain Bitton MD, McGill University, Montreal, Quebec \\
Brian Feagan MD, University of Western Ontario, London, Ontario \\
Subrata Ghosh MD (Chair), University of Calgary, Calgary, Alberta \\
Remo Panaccione MD, University of Calgary \\
Crohn's and Colitis Foundation of Canada staff \\
Kevin W Glasgow MD, Chief Executive Officer \\
Aida Fernandes MBA, Chief Science and Education Officer \\
Fiona Knight MPPA, Manager, Public Policy \& Stakeholder Relations \\
Tina Smith, Research \& Education Assistant \\
External researcher \\
Angela Rocchi MSc, Axia Research, Burlington, Ontario \\
\hline
\end{tabular}

continuing symptoms, reduction in the ability to work, social stigma, bathroom access issues, difficulty with physical intimacy and restriction in career choices.

In Canada, there is a lack of public awareness of the impact of CD and UC. Raising awareness is important to reduce the social stigma that is common with these diseases and to help individuals maximize their overall quality of life. To fulfill this vision, the Crohn's and Colitis Foundation of Canada (CCFC) led an effort to gather and share high-quality, current and relevant information on IBD. Canadians have conducted landmark IBD research - much of which has been funded by the CCFC and its partners. This work aims to raise awareness and understanding of IBD in Canada to create new research opportunities and to improve quality of life for people with IBD. The present report builds on, updates and extends the CCFCcommissioned report from 2008 titled The Burden of Inflammatory Bowel Disease in Canada (1).

\section{METHODS}

Similar methodology was used for both the original Burden of Inflammatory Bowel Disease in Canada report in 2008 and for the present update. A steering committee was formed to lead the project (Table 1) and to identify relevant topics for review. The scientific literature was searched using an electronic database (PubMed) with a specific focus on identifying Canadian-based research. Search terms included: Canada AND (IBD OR Crohn's disease OR ulcerative colitis) AND (epidemiology OR burden OR cost OR economic OR quality of life OR utility OR pediatric). Additionally, conference proceedings and public websites (both government and nonprofit) were reviewed or accessed for additional findings. A private database of drug claims (IMS Brogan Pharmastat) (2) was used to assess the public and private costs of medications used to treat IBD.

For direct medical costs, a private database of national private and public drug claims was analyzed to determine annual costs for IBDspecific drugs: biologicals (adalimumab, infliximab); immunomodulators (azathioprine, cyclosporine, 6-mercaptopurine, methotrexate); 5 -aminosalicylic acid products (mesalamine, sulfasalazine); and steroids (budesonide). In cases for which these drugs have multiple indications, the total number of claims was factored according to the percentage of use that was specific to IBD. (Note: certolizumab was excluded from the analysis because it is not indicated for CD and, thus, has minimal use for CD in Canada). Quantity and cost of utilization for hospitalizations, surgeries and physician visits were determined from a recent database study conducted in Manitoba (3). Costs for miscellaneous medical resources were generally not well studied and, as such, were estimated from research conducted in the United Kingdom and Australia.

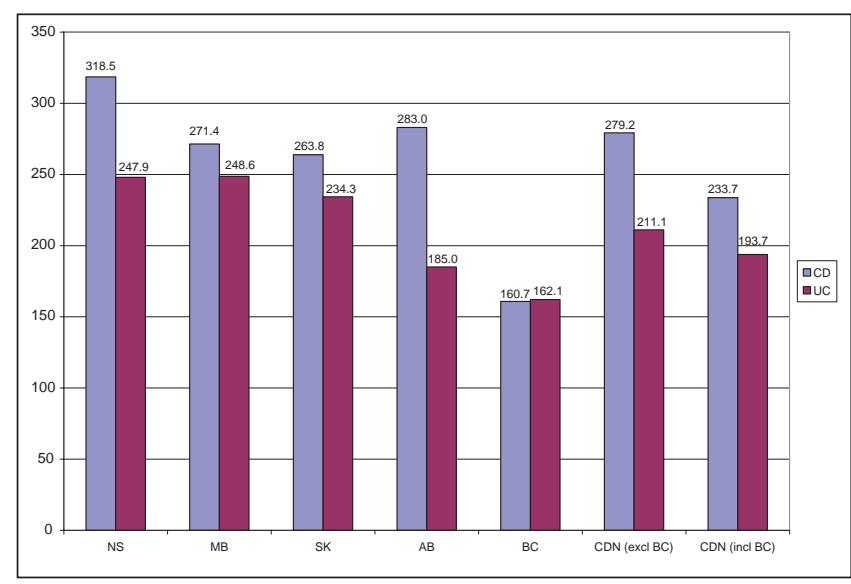

Figure 1) Prevalence per 100,000 population according to province. Data adpated from references 6 and 7. AB Alberta; BC British Columbia; CD Crohn's disease; CDN Canadian; excl Excluding; incl Including; MB Manitoba; NS Nova Scotia; SK Saskatchewan; UC Ulcerative colitis

Indirect costs were divided into the following categories: shortterm work losses; long-term work losses (including premature retirement); premature mortality; caregiver support; and patient out-of-pocket expenses. Some of these were not well studied in Canada (with the exception of long-term work losses), which required reliance on data from other countries. Research has been conducted in several countries for long-term work loss; however, data collected in Canada were selected for use. In all cases, literature-based estimates of indirect resources (eg, patient days lost from work, caregiver days lost from work) were assigned a Canadian cost per workday and extrapolated to the Canadian IBD population. For premature mortality, the estimated number of premature deaths in Canada was determined and an opportunity cost was assigned for lost workplace participation.

Analyses were applied or extrapolated to the current 2012 Canadian population. Current Canadian figures were used (eg, Canadian average wage rate as reported by Statistics Canada, drug costs as generated by the Pharmastat database) (4). Where necessary, costs were adjusted using the health and personal care component of the Consumer Price Index (5).

\section{Epidemiology}

\section{RESULTS}

Canada has among the highest frequencies of $\mathrm{CD}$ and $\mathrm{UC}$ in the world.

There are two main sources of data for the epidemiology of IBD in Canada: the Canadian Community Health Survey (which was conducted nationwide) and the Canadian IBD Epidemiology Database Study (conducted in five provinces) $(6,7)$. It is well recognized that survey data inaccurately overestimate disease prevalence; therefore, the IBD Database Study was used exclusively as the basis to estimate Canadian prevalence and incidence rates.

\section{Prevalence}

For the year 2000, the IBD Epidemiology Database Study estimated the prevalence of IBD to be $0.47 \%$ of the population ( 279 per 1000 for CD; 211 per 1000 for UC), with relatively consistent prevalence across the country, although a markedly lower prevalence of $\mathrm{CD}$ was identified in British Columbia (BC) (7). The Canadian average was estimated by excluding BC. Subsequently, similar research was completed in Quebec for CD, with results similar to the provinces exclusive of BC (a prevalence of 243 per 1000). Provincial and national prevalence proportions are presented in Figure 1. Overall, females were more likely to have CD than males ( 1.3 females: 1 male) but there was no sex difference for UC (7). 


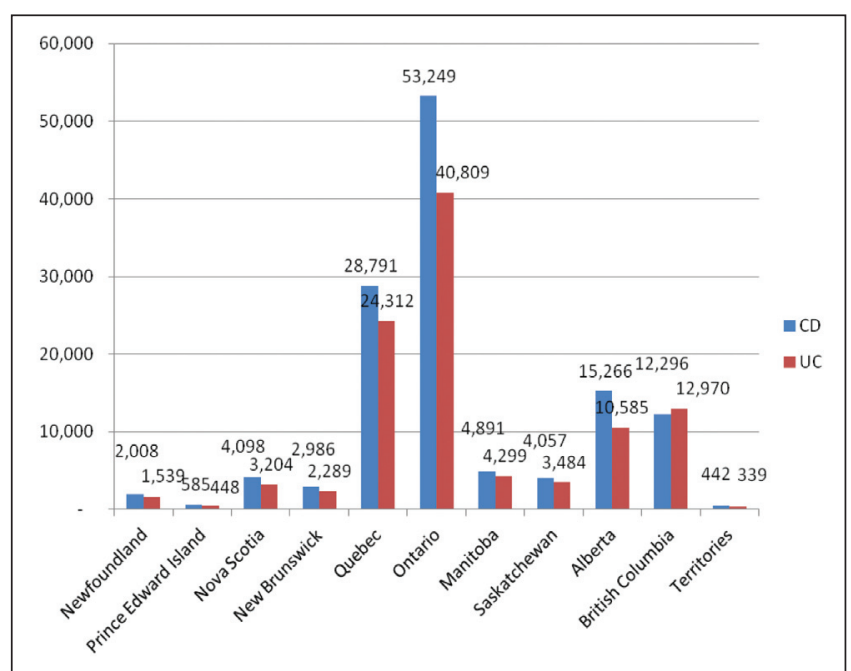

Figure 2) Prevalence of inflammatory bowel disease (Crohn's disease [CD], Ulcerative colitis [UC]) according to province in 2012. Prevalences directly estimated from the Canadian IBD Epidemiology Database study for British Columbia, Alberta, Saskatchewan, Manitoba and Nova Scotia, and from reference 8 for Quebec; extrapolated for Newfoundland and Labrador, Prince Edward Island, New Brunswick, Ontario and the Territories

For 2012, the current Canadian prevalence of IBD was estimated using data from the IBD Epidemiology Database Study, with adjustments for population increases and the diagnosis of new cases (assuming an estimated net increase of IBD of 17 cases per 100,000). Accordingly, in 2012, an estimated 233,000 Canadians had IBD (129,000 with CD and 104,000 with UC), corresponding to a prevalence of $0.67 \%$. The number of individuals with IBD per province is illlustrated in Figure 2.

\section{Incidence}

Incidence rates were based on data from the the IBD Epidemiology Database Study plus the Quebec study and followed the same pattern as prevalence. The national average incidence rate from 1998 to 2000 was 16.3 per 100,000 for CD and 12.9 per 100,000 for UC, with lower rates in $\mathrm{BC}(7)$. Thus, there are approximately 10,200 new cases of IBD diagnosed each year: 5700 with CD and 4500 with UC.

\section{Age of onset/distribution}

The highest incidence of CD occurs in the third decade of life (7). Conversely, there is no single peak age of onset for UC: there is an initial peak in the second decade of life, followed by a plateau, and possibly a second peak in later years (7).

$\mathrm{CD}$ and $\mathrm{UC}$ can be diagnosed at a young age, but new cases continue to appear in older ages. As a result, the prevalence remains high in older age groups (7). The prevalence climbs to peak levels by 30 years of age and remains at this level until after 80 years of age (7).

\section{Pediatric IBD}

Although most commonly presenting in young adults, IBD often presents before the third decade of life, even in children as young as six months of age. The Ontario Crohn's and Colitis Cohort reported a high and steadily increasing prevalence of IBD in children - Canada has one of the highest rates of childhood-onset IBD in the world (9). Similar to adults, CD was more common than UC; however, unlike adults, IBD was more common in male children. Male predominance has also been observed in other international studies $(10,11)$. This pattern changes at puberty, with an increase in female cases compared with male cases. Incidence is increasing significantly in the youngest age groups (children $<10$ years of age). There are an estimated 5900 children with IBD who are $<18$ years of age in Canada in 2012.

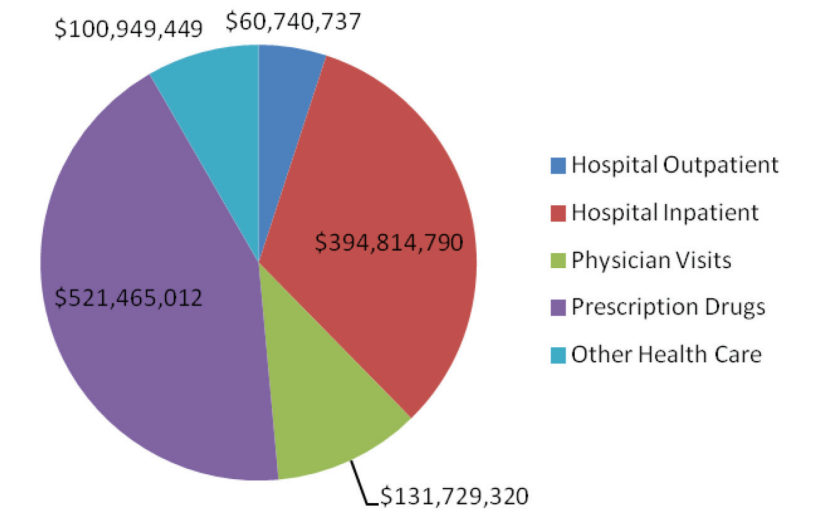

Figure 3) Direct costs of inflammatory bowel disease in Canada in 2012

\section{Mortality}

A meta-analysis of 10 mortality studies involving CD determined that CD was associated with a statistically significant, $47 \%$ increase in mortality risk (12). These results were confirmed in a subsequent second meta-analysis of 13 studies, which found a 52\% risk increase (13), as did two later large studies $(14,15)$. A meta-analysis of eight mortality studies involving UC, plus an additional two studies published since the meta-analysis, found no excess risk of premature mortality for UC, although an increased risk of colon cancer was present $(14,16)$.

\section{International comparisons}

A recent comprehensive review of international research in IBD epidemiology established that Canadian results were consistently in the highest quintile (top 20\%) for both incidence and prevalence of CD and UC (17). Others in this quintile are mostly northern European countries, Australia and the United States. The lowest quintile include Asian and other developing countries that had contributed data to the analysis. Similarly, results for pediatric IBD demonstrated that Canadian rates were, again, in the top quintile (18).

\section{Direct medical costs}

Direct medical costs include services provided by the Canadian public health care system such as hospitalizations, surgeries, physician visits, medications, laboratory tests and procedures, other health care professionals, social services and long-term care facilities.

Currently, there is no cure for CD or UC. Individuals with IBD live with symptoms at a milder level while in remission and at a more severe level during disease flares. Between $75 \%$ and $90 \%$ of patients are in remission at any given point in time (19). To manage their disease, even while in remission, individuals with IBD need continuing medical care. With increasing disease activity and flares, medications are increased and hospitalizations for surgery become common.

Total direct medical costs topped $\$ 1.2$ billion in 2012 (Figure 3). Drug costs accounted for the single largest component, followed by inpatient hospitalization; together, they constituted $76 \%$ of the total direct medical costs of IBD. The increased proportion of direct costs attributable to medication is a dramatic shift from one decade previously, when costs resulting from the provision of care to inpatients was the dominant expenditure. The causes for this reflect the advent and uptake of biological drugs in the past decade, which have high acquisition costs, as well as changes in care delivery (including a reduced number of hospitalizations).

\section{Pharmaceuticals}

The use of biological drugs (ie, infliximab and adalimumab) has increased dramatically in recent years, and current data are required to accurately estimate pharmaceutical expenditures. A national drug claims database was used to identify prescriptions for the typical drugs 


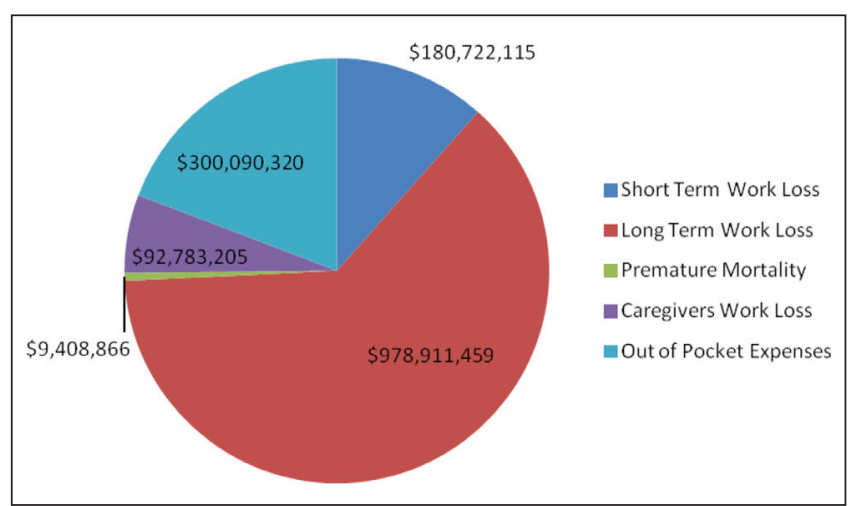

Figure 4) Indirect costs of inflammatory bowel disease, Canada 2012

used to treat IBD (20). Many of these drugs are used for non-IBD diseases; accordingly, total cost was factored according to the percentage of use that was specific to IBD indications. Drug claims data across public and private payers showed that costs for the most recent year (ie, 2011) totalled $\$ 460$ million. Approximately $84 \%$ of these costs were for the biological drugs infliximab and adalimumab. There has been steady and significant growth in drug costs over the past several years because biologicals have become the standard of care for individuals with more severe disease. Using conservative growth estimates, prescription drug claim costs are projected to be $\$ 521$ million in 2012. This figure excludes costs for patients who pay out of pocket for drugs (ie, those who have neither a public nor a private drug plan to pay for their drugs). However, at least for the biologicals, most people cannot afford to pay out of pocket; therefore, these products are generally covered by provincial or private sector drug plans.

There were important differences observed in costs across the country, with per-capita drug costs twice as high in some provinces compared with others. There was also a threefold difference among provinces in the percentage of drug costs that were covered by public plans versus private plans. This is related to the differences between the provincially administered public drug plans, in both the type of drug that is funded and the extent of the population that is covered.

Drug access may be an issue in treatment decisions. A study involving children with IBD (21) found that socioeconomic status played an important role. Children from lower-income households were more likely to be hospitalized, visit the emergency room, see their physician and undergo surgery.

\section{Hospitalizations, surgeries and physician visits}

Researchers in Manitoba reviewed health records for individuals who had been identified as having IBD over several time points, with the most recent data from 2005/2006 (3,22). Health records were examined to determine the annual costs of hospitalizations, surgeries, physician visits and drugs. For these four items, people with IBD incurred an average of $\$ 3,896$ in direct medical costs in 2005/2006 (3). This amount was twice that of people without IBD (matched for age and sex). CD was more expensive than UC $(\$ 4,232$ versus $\$ 3,522)$. Although mean costs were higher for people with CD, it appeared that this was due to the higher costs for outlier CD cases - the median costs per case for $\mathrm{CD}$ and $\mathrm{UC}$ were actually quite similar.

The most expensive cases fell into four categories: individuals in their first year postdiagnosis $(\$ 6,611)$; those who were hospitalized overnight $(\$ 13,494)$; those who underwent surgery $(\$ 18,749)$; and those using infliximab $(\$ 31,440)$. As is typical in costing studies, a small minority of patients accumulated a disproportionate amount of cost - in the case of the present study, 11\% of IBD cases contributed to $56 \%$ of total costs.

As mentioned above, more recent data were used to estimate drug costs. Therefore, the costs due to drug therapy were removed from the total. The Manitoba study was essential for the estimation of inpatient hospitalization, outpatient hospitalization (same-day stays and procedures) and physician visits. After subtracting drug costs, the average cost for these three items was $\$ 2,260$ in 2005/2006 (corresponding to $\$ 2,521$ per person adjusted to 2012 dollars). Of this amount, $67 \%$ was due to hospitalization, $22 \%$ to doctor visits and $10 \%$ to outpatient visits. Extrapolated to the 233,000 Canadians with IBD, the total cost for these items is $\$ 587$ million ( $\$ 395$ million for hospital inpatient, $\$ 132$ million for physician visits and $\$ 61$ million for hospital outpatients).

Historically, hospitalizations and surgeries were inevitable for most IBD patients given the lack of treatment options. A Canadian survey was conducted in individuals with IBD who had a mean duration of disease of 18 years for $\mathrm{CD}$ and 15 years for UC. Among those with CD, $84 \%$ had been hospitalized and $65 \%$ had undergone surgery. For people with UC, $51 \%$ had been hospitalized and $16 \%$ had undergone surgery (23). For those with an IBD-related hospitalization, 58\% occurred within the first two years of diagnosis, with $36 \%$ of the surgeries also occurring within the first two years (24).

Surgery rates as an outcome may be changing, at least for those with CD. Surgical rates have been falling globally and, because one-half of all CD hospitalizations involve surgery, the rate of hospitalization has fallen concurrently (25). This may be due to earlier diagnosis, improved access to specialist care or the impact of newer therapies. Individuals diagnosed with CD since 2001 were significantly more likely to see a gastroenterologist within the first year of diagnosis and have less need for surgery and associated hospitalizations (26). They also incurred higher use of immunosuppressives and biologicals. Specialist care from the outset of the disease is associated with these trends to reduced surgery and earlier use of more effective medical therapy.

In recent years, children with IBD have had more contact with pediatric gastroenterologists (rather than adult gastroenterologists), which likely yields improved overall care and better outcomes. Since the 1990s, there has been a stable rate of age-adjusted hospitalizations among children with IBD, but there has been a 30\% decrease in the need for surgery in children with CD. No such decrease in the surgical rate has been observed for children with UC. Finally, children are more likely to receive immunosuppressives and biological therapy than has previously been documented (27).

\section{Other costs}

Other health care system costs have not been studied in Canada (ie, laboratory tests and procedures, nonphysician professional services, home care, long-term care, etc). An Australian study of IBD patients reported on the use of institutional care and other health care professionals (12). Emergency room visits were measured in an American study of CD patients using records from a health maintenance organization (28). By extrapolation, other costs were estimated to total $\$ 101$ million for Canada in 2012, corresponding to $\$ 433$ per person per year.

\section{Indirect costs}

Indirect costs are those that are borne by people and by society rather than the health care system. Total indirect costs topped $\$ 1.6$ billion in 2012 (Figure 4). Lower labour participation rates were the largest component of this cost ( $\$ 979$ million [61\% of the total]), followed by patient out-of-pocket expenses ( $\$ 300$ million).

\section{Short-term work losses}

There have been nine studies reporting on short-term work losses in IBD conducted in Canada, Australia and Western Europe. On average, $43 \%$ of employed people with IBD took time off work per year, and each employed person with IBD was absent 7.2 days per year directly attributable to IBD (irrespective of absences for other reasons) (12). Applying an average IBD labour participation rate of $60 \%$, and using the average daily wage rate (4), this translated into \$181 million per year for the 140,000 actively employed individuals with IBD. 


\section{Long-term work losses}

Seven studies conducted in Canada, Australia, Europe and the United States have reported on long-term work losses in IBD. The reduction in the probability of employment ranged from $3 \%$ to $13 \%$ (12). In Canada, this rate was estimated to be $9 \%$ (29). This would translate into 21,000 people with IBD who had withdrawn from the workforce since their diagnosis and were more likely to be unemployed, disabled or prematurely retired. Using the mean wage rate, this converts to $\$ 979$ million in lost wages in 2012. Although these long-term departures from the workforce may be managed with permanent replacement workers, employers continue to bear costs due to disability pensions and long-term disability costs. Recent research on disability rates in Norway found that 10 years after diagnosis, $19 \%$ of people with IBD received a disability pension (30). This research supports the principle that society incurs continuing costs for IBD. As individuals withdraw from the workforce and are replaced by other workers, employers and income-assistance programs continue to bear the burden of IBD disability.

\section{Premature mortality}

From a purely economic standpoint, premature mortality from IBD can cause productivity losses to society. In Canada, there were an average of 85 deaths due to CD and 43 deaths due to UC per year from 2004 to 2008 (most recent available data) (31). Of these, there were an average of 30 deaths from CD and 14 deaths from UC in individuals $<65$ years of age. Based on the mortality analysis, UC does not cause excess mortality; therefore, the focus was on CD only.

Of the 30 deaths per year due to $\mathrm{CD}$, and using an employment estimate of $60 \%$ in people with IBD, there would be 18 deaths in potentially employable people with $\mathrm{CD}$. The average age at death was 49 years for those who died before 65 years of age; this corresponds to 16 years of lost employment. The productivity loss is estimated to be $\$ 523,000$ per person, corresponding to $\$ 9.4$ million for all 18 premature deaths each year.

\section{Caregivers}

Caregivers are people who provide informal (unpaid) care to others who need assistance for health reasons. Caregivers are needed for those most severely affected by IBD, and also for children with IBD (whose parents would need to be involved in their care). However, few data exist that quantify the economic impact of IBD on caregivers.

For pediatric cases of IBD, at least one parent would be involved in the care of the affected child. If the typical employed person with IBD required 7.2 days per year of sick leave for their own disease management (12), it was assumed that the same number of days would be required to manage a child's illness. Parents of children with IBD were assumed to have a labour participation rate equal to the general public $(81.5 \%$ as per large national surveys in Canada and the United States $[32,33])$. An average work wage should be assigned to employed parents while a minimum wage is typically assigned to nonemployed individuals (eg, homemakers) (4). Minimum expected caregiver costs for parents of children with IBD total $\$ 7$ million for parents of the estimated 5900 children with IBD in Canada in 2012.

For individuals severely affected by IBD, there are survey data from an Australian study on caregivers that suggest one caregiver per 100 persons with IBD (presumably, those with the most severe disease who would be unable to function normally). Overall, primary caregivers in the survey averaged $30 \mathrm{~h}$ per week caring for people with disabilities. Assuming that $1 \%$ of people with IBD required $30 \mathrm{~h}$ per week for caregiving, the estimated 233,000 Canadians with IBD (2330 severely ill) would incur a cost of approximately $\$ 86$ million (at minimum wage) for care giving.

\section{Patient out-of-pocket expenses}

Only a few studies have examined out-of-pocket expenses for people with IBD. These expenses include ostomy supplies, home aids and modifications, formal care (housekeeping, daycare, etc), travel for medical appointments, nutritional products, and complementary and alternative medicines.
A survey of CCFC members found that use of complementary and alternative medicines was quite common (35). Approximately $24 \%$ of people with IBD are current users of these medicines (albeit not exclusively for IBD treatments) (36) and incur an average cost of $\$ 568$ per year. This converts to $\$ 136$ per person with IBD, corresponding to $\$ 32$ million per year.

A German population study surveyed people with IBD regarding a broad range of costs including out-of-pocket expenses such as travel, household support and patient activities. The mean cost per four weeks was $€ 50$ per peson with $\mathrm{CD}$ and $€ 46$ per person with UC (2004€) - corresponding to $€ 624$ per person per year (37). This corresponds to $\$ 1,152$ per year (2012CAD $\$$ ) - a total cost of $\$ 268$ million per year for the 233,000 people with IBD in Canada.

\section{Quality of life}

Beyond out-of-pocket expenses, individuals with IBD also experience tremendous additional personal cost, that is, the burden of having a disease. There are medical issues to contend with that range from the experience of symptoms (pain, diarrhea, fatigue) to the worry about how the course of the disease will affect their future. The fluctuating and unpredictable nature of IBD can make it very difficult to plan for the future, negatively affecting choices with respect to career, travel and other personal options.

Based on survey data derived using a disease-specific questionnaire (ie, Inflammatory Bowel Disease Questionnaire), it is evident that quality of life is most strongly affected by the severity of disease (38-40). Furthermore, women with IBD are more likely to experience a lower quality of life than men with $\operatorname{IBD}(39,40)$. It is important to note that quality of life is reduced even in those who do not experience physical symptoms (due to fluctuating disease or medication-induced remission). Even those without symptoms experience psychological distress (stress, anxiety, fear about pain and worry about the consequences of their disease) $(41,42)$. Poor sleep quality is very common in people with IBD, regardless of whether their disease is active (43).

Children with IBD have a reduced quality of life, as do children with other diseases; however, teenagers with IBD are most strongly affected $(44,45)$.

Effective treatments are associated with a normalization in quality of life, both for $\mathrm{CD}$ and for UC; this has been demonstrated for surgery $(46,47)$, conventional drugs such as immunosuppressives (48) and biologicals agents (49-51).

Compared with the general population, people with both CD and UC scored lower on the generic quality of life measure, the Short Form-36 (52). Scores were lowest for those with more severe disease. Scores were significantly lower for almost all of the eight different aspects of quality of life measured by the Short Form-36. Similar results were observed using utility instruments $(53,54)$. People with severe disease scored very low $(0.45)$, which indicates a very significant impairment in quality of life. People with mild disease scored 0.68 , typical of many chronic diseases, while those in remission scored 0.77 - still well below the population average of 0.85 (Figure 5) (55).

\section{DISCUSSION}

The present review documents a high burden of illness from IBD due to the frequency of IBD occurrence in Canada combined with high per-patient costs. The total costs of IBD in Canada in 2012 were $\$ 2.8$ billion, corresponding to almost $\$ 12,000$ for every person with IBD, of which direct medical costs were $44 \%$ and indirect costs were $56 \%$.

Canada continues to have among the highest incidence and prevalence of IBD in the world - currently at $0.67 \%$ and growing. Canada's high incidence means that the number of cases will continue to grow within the existing population, beyond population growth. In addition, research from immigrant communities shows that second-generation immigrants assume the high incidence rate of the Canadian population - even for those from countries with low endemic rates of IBD. For an immigration-dependent nation such as Canada, this is a 


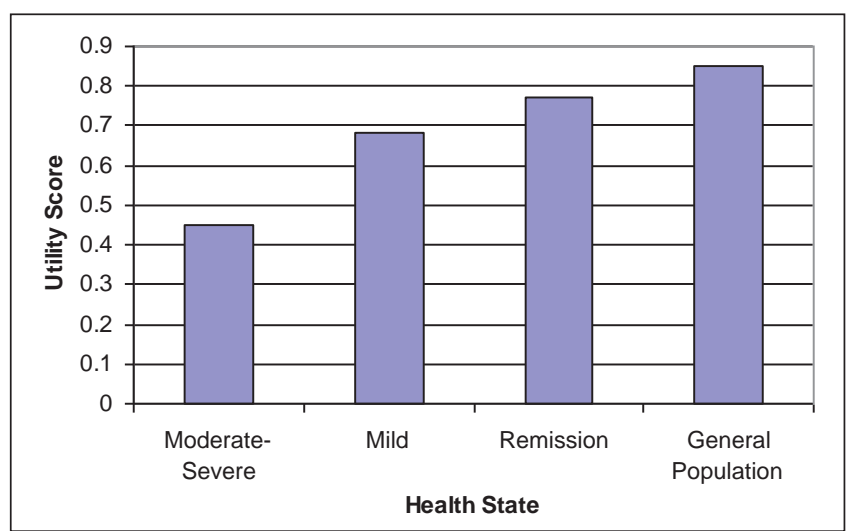

Figure 5) Utility scores for Crohn's disease versus the general population

troubling observation. These findings warrant further investigation and may even yield important clues as to the cause of IBD.

The present report includes important recent findings on pediatric IBD epidemiology. There is significantly increasing incidence in the youngest of children (ie, those $<10$ years of age) - a worrisome finding, and another important area of further research. The careful investigations that have been performed in IBD epidemiology confirm that Canadian children are developing IBD at among the highest rates in the world. There is an urgent need to explore why and how these cases are developing in our country.

Another new finding is the shift in direct medical expenses. Surgery is no longer an inevitable consequence of CD. Improved utilization of specialist care and increased use of biological drugs appears to be improving outcomes by reducing surgeries and hospitalizations. As a result, hospitalization costs have decreased as a proportion of direct medical expenditures, and pharmaceutical costs have increased. Given that the uptake of biological drugs occurred later for UC than for CD, these trends may eventually be observed for UC as well. Unfortunately, these improvements may not have been achieved equally across the country. Specialist access is often geographically dependent; variable rates of retirement versus intake also affect specialist availability. Furthermore, Canada's universal health care system does not extend to drugs. There is uneven and inequitable access to drug funding among the provinces and between public/private insurance claimants. Access to biologicals may contribute to the improved health outcomes that have been observed with IBD, but this access is heterogenous, leading to unacceptable disparities in treatment options and access.

Overall, the economic impact of IBD is enormous and is increasing. The present report documented increases in direct medical costs, which were accompanied by improved health outcomes. Indirect costs are also high, and reflect the human component of frustrated career plans, reduced employment options, and ongoing anxiety about the unpredictability of symptoms and disease course, all under the umbrella of a chronic disease with social stigma and relative lack of awareness and funding. In contrast, Canada is also known as a nation with high rates of multiple sclerosis - a disease with high national awareness and intense media interest accompanied by substantial research funding. There are three times as many Canadians with IBD than there are with multiple sclerosis, yet this is not reflected in the degree of public attention or support.

Canada is an international leader in IBD research, with a significant volume of landmark, peer-reviewed publications and a disproportionate concentration of world-class researchers and centres of excellence. These remarkable achievements have occurred despite limited access to health administrative data across the country. The quality and significance of this research strongly support improvements in national access to health administrative data.
There are significant challenges faced by individuals with IBD, family members and caregivers across Canada, as well as research and health service delivery challenges. The critical common challenges facing the IBD community include the following:

- Awareness of IBD - low recognition that IBD is a chronic disease resulting in unnecessary social stigma.

- Access to IBD specialists and procedures - regional disparities and untimely access to care, including delayed diagnosis or inappropriate diagnosis.

- Access to IBD medications - high and cost-prohibitive medication expenses, and variable access and coverage among private health insurance and provincial public drug plans across the country.

- Employment issues - vulnerable IBD employees due to their youth and lack of seniority for employment protection.

- Support for people with IBD and their caregivers - absence of community-based support mechanisms, particularly for parents of children with IBD.

- Research - limited resources to study the 'cause, care and cure' of IBD, and inadequate support for monitoring and evaluation research to improve estimates of prevalence and costs of IBD.

\section{CONCLUSION}

The burden that IBD places on individuals, the health care system and society is significant and will continue to grow as the number of patients with IBD increases. Government, media, the general public and other like-minded stakeholders must mobilize to address current issues and improve the current landscape of IBD in Canada.

Canada is an epicentre of IBD, with some of the world's highest rates and some of the world's best researchers. It behooves us to devote public attention, research and funding to treat and support those with IBD and understand how to prevent future cases.

FUNDING: The Crohn's and Colitis Foundation of Canada (CCFC) is a registered national charity that is dedicated to finding cures for, and improving the lives of, persons affected with IBD. This review was funded by CCFC, with partial funding from unrestricted educational grants from Rx\&D and Abbott Canada. This acknowledgement, however, does not constitute an endorsement of the sponsoring organizations' products or services. Axia Research was contracted by CCFC to write the report, compile data and conduct analyses. All the other authors have not received any honorarium for their contribution to developing this review.

ADDITIONAL CONTRIBUTORS: Fiona Knight, Manager, Public Policy and Stakeholder Relations, CCFC

\section{REFERENCES}

1. Crohn's and Colitis Foundation of Canada. The Impact of Inflammatory Bowel Disease in Canada. Final report and recommendations. <www.cfc.ca> (Accessed November, 2008).

2. IMS Brogan Canada Inc. Pharmastat database. Ottawa: 2012. (Accessed June 2012).

3. Bernstein CN, Longobardi T, Finlayson G. Direct medical cost of managing IBD patients: A Canadian population-based study. Inflamm Bowel Dis 2011; e-published Nov 22.

4. Statistics Canada. Earnings, average weekly, by province and territory. CANSIM table 281-0027. <www.statcan.ca> (Accessed May, 2012).

5. Statistics Canada. Consumer price index. Health and personal care component. <www.statcan.ca> (Accessed May 2012).

6. Canadian Community Health Survey 2005. Statistics Canada.

7. Bernstein CN, Wajda A, Svenson LW, et al. The epidemiology of inflammatory bowel disease in Canada: A population-based study. Am J Gastroenterol 2006;101:1559-68.

8. Lowe AM, Roy PO, Poulin MB et al. Epidemiology of Crohn's disease in Quebec, Canada. Inflamm Bowel Dis 2009;15:429-35. 
9. Benchimol EI, Guttmann A, Griffiths AM, et al. Increasing incidence of paediatric inflammatory bowel disease in Ontario, Canada: Evidence from health administrative data. Gut 2009;58:1490-7.

10. Lehtinen P, Ashorn M, Iltanen S, et al. Incidence trends of pediatric inflammatory bowel disease in Finland, 1987-2003, a nationwide study. Inflamm Bowel Dis 2011;17:1778-83.

11. Henderson P, Hansen R, Cameron FL, et al. Rising incidence of pediatric inflammatory bowel disease in Scotland. Inflamm Bowel Dis 2012;18:999-1005.

12. Australian Crohn's and Colitis Association. The economic costs of Crohn's disease and ulcerative colitis. <www.acca.net.au> (Accessed June 2007).

13. Canavan C, Abrams KR, Mayberry JF. Meta-analysis: Mortality in Crohn's disease. Aliment Pharmacol Ther 2007;25:861-70.

14. Hutfless SM, Weng X, Liu L, et al. Mortality by medication use among patients with inflammatory bowel disease. Gastroenterology 2007;133:1779-86.

15. Jess T, Riis L, Vind I, et al. Changes in clinical characteristics, course, and prognosis of inflammatory bowel disease during the last 5 decades: A population-based study from Copenhagen, Denmark. Inflamm Bowel Dis 2007;13:481-9.

16. Hoie O, Schouten LJ, Wolters FL, et al. Ulcerative colitis: No rise in mortality in a European-wide population based cohort ten years after diagnosis. Gut 2007;56:497-503.

17. Molodecky NA, Soon IS, Rabi DM, et al. Increasing incidence and prevalence of the inflammatory bowel diseases with time, based on systematic review. Gastroenterology 2012;142:46-54.

18. Benchimol EI, Fortinsky KJ, Gozdyra P, et al. Epidemiology of pediatric inflammatory bowel disease: A systematic review of international trends. Inflamm Bowel Dis 2011;17:423-39.

19. Silverstein MD, Loftus EV, Sandborn WJ, et al. Clinical course and costs of care for Crohn's disease: Markov model analysis of a population-based cohort. Gastroenterology 1999;117:49-57.

20. IMS Brogan Inc. Pharmastat Prescription Database. Ottawa, 2012. Data on file.

21. Benchimol EI, To T, Griffiths AM, et al. Outcomes of pediatric inflammatory bowel disease: Socioeconomic status disparity in a universal-access healthcare system. J Pediatr 2011;158:960-7.

22. Longobardi T, Bernstein CN. Health care resource utilization in inflammatory bowel disease. Clin Gastroenterol Hepatol 2006;4:731-43.

23. Hilsden RJ, Verhoef MJ, Best A, et al. A national survey on the patterns of treatment of inflammatory bowel disease in Canada. BMC Gastroenterol 2003;3:10.

24. Longobardi T, Bernstein CN. Utilization of health-care resources by patients with IBD in Manitoba: A profile of time since diagnosis. Am J Gastroenterol 2007;102:1683-91.

25. Bernstein CN, Loftus EV, Ng SC, et al. Hospitalization and surgery in Crohn's disease. Gut January 20, 2012 (E-pub ahead of print).

26. Nguyen GC, Nugent Z, Shaw S, et al. Outcomes of patients with Crohn's disease improved from 1988 to 2008 and were associated with increased specialist care. Gastroenterology 2011;141:90-7.

27. Benchimol EI, Guttmann A, To T, et al. Changes to surgical and hospitalization rates of pediatric inflammatory bowel disease in Ontario, Canada (1994-2007). Inflamm Bowel Dis 2011;17:2153-61.

28. Feagan BG, Vreeland MB, Larson LR, et al. Annual cost of care for Crohn's disease: A payor perspective. Am J Gastroenterol 2000;95:1955-60.

29. Wyke R, Edwards F, Allan R. Employment problems and prospects for patient with IBD. Gut 1988;29:1756.

30. Hoivik ML, Mourn B, Solberg IC, et al. Work disability in inflammatory bowel disease patients 10 years after disease onset: Results from the IBSEN study. Gut June 20, 2012 (E-pub ahead of print).

31. Statistics Canada. Deaths, by cause, Chapter XI: Diseases of the digestive system (K00 to K93) age group and sex, Canada, annual (number). Table 102-0531. <www.statcan.ca> (Accessed May 2008).

32. Longobardi T, Jacobs P, Wu L, et al. Work losses related to IBD in Canada: Results from a National Population Health Survey. Am J Gastroenterol 2003;98:844-9.

33. Longobardi T, Jacobs P, Bernstein CN. Work losses related to IBD in the United States: Results from the National Health Interview Survey. Am J Gastroenterol 2003;98:1064-72.
34. Australian Bureau of Statistics. Survey of Disability, Ageing and Careers, 2003 (unpublished data).

35. Hilsden RJ, Verhoef MJ, Best A, et al. Complementary and alternative medicine use by Canadian patients with IBD: Results from a national survey. Am J Gastroenterol 2003;98:1563-8.

36. Rawsthorne P, Clara I, Graff LA, et al. The Manitoba Inflammatory Bowel Disease Cohort Study: A prospective longitudinal evaluation of the use of complementary and alternative medicine services and products. Gut 2012; 61:521-7.

37. Stark R, Honig H, Leidl R. Costs of IBD in Germany. Pharmacoeconomics 2006;24:797-814.

38. Vidal A, Gomez-Gil E, Sans M. Health-related quality of life in inflammatory bowel disease patients: The role of psychopathology and personality. Inflamm Bowel Dis 2008;14:977-83.

39. Bernklev T, Jahnsen J, Adland E, et al. Health-related quality of life in inflammatory bowel disease patients five years after the initial diagnosis. Scand J Gastroenterol 2004;39:365-73.

40. Saibeni S, Cortinovis I, Beretta L, et al. Gender and disease activity influence health-related quality of life in inflammatory bowel diseases. Hepatogastroenterology 2005;52:509-16.

41. Lix LM, Graff LA, Walker JR, et al. Longitudinal study of quality of life and psychological functioning for active, fluctuating and inactive disease patterns in inflammatory bowel disease. Inflamm Bowel Dis 2008;14:1575-84.

42. Graff LA, Walker JR, Lix LM. The relationship of inflammatory bowel disease type and activity with psychological functioning and quality of life. Clin Gastroentrol Hepatol 2006;4:1491-501.

43. Graff LA, Vincent N, Walker JR, et al. A population-based study of fatigue and sleep difficulties in inflammatory bowel disease. Inflamm Bowel Dis 2011;17:1882-9.

44. Loonen HJ, Grootenhuis MA, Last BF. Quality of life in paediatric inflammatory bowel disease measured by a generic and a diseasespecific instrument. Acta Paediatr 2002;91:348-54.

45. De Boer M, Grootenhuis M, Derkx B, et al. Health-related quality of life and psychosocial functioning in adolescent boys with inflammatory bowel disease. Inflamm Bowel Dis 2005;11:400-6.

46. Scarpa M, Ruffolo C, D'Inca R, et al. Health-related quality of life after ileocolonic resection for Crohn's disease: Long-term results. Inflamm Bowel Dis 2007;13:462-9.

47. Camilleri-Brennan J, Steele RJ. Objective assessment of quality of life after panproctocolectomy and ileostomy for ulcerative colitis. Ann R Coll Surg Engl 2001;83;321-4.

48. Bernklev T, Jahnsen J, Schulz T, et al. Course of disease, drug treatment and health-related quality of life in patients with inflammatory bowel disease five years after initial diagnosis. Eur J Gastroenterol Hepatol 2005;17:1037-45.

49. Feagan BG, Rainisch W, Rutgeerts P, et al. The effects of infliximab therapy on health-related quality of life in ulcerative colitis patients. Am J Gastroenterol 2007;102:794-802.

50. Rutgeerts P, Schreiber S, Feagan B, et al. Certolizumab pegol, a monthly subcutaneously administered Fc-free anti-TNFa, improves health-related quality of life in patients with moderate to severe Crohn's disease. Int J Colorectal Dis 2008;23:289-96.

51. Colombel JF, Loftus EV, Feagan BG, et al. Impact of adalimumab (Humira ${ }^{\circledR}$ ) on patient-reported outcomes among patients with fistulizing Crohn's disease in the Charm trial. Gut 2007;56(Suppl III):A149.

52. Bernklev T, Jahnssen J, Lygren I. Health-related quality of life in inflammatory bowel disease patients measured with the short-form 36: Psychometric assessments and comparison with general population norms. Inflamm Bowel Dis 2005;11:908-11.

53. Gibson PR, Weston AR, Shann A, et al. Relationship between disease severity, quality of life and health-care resource use in a cross-section of Australian patients with Crohn's disease. J Gastroenterol Hepatol 2007;22:1306-12.

54. Buxton MJ, Lacey LA, Feagan BG, et al. Mapping from diseasespecific measures to utility: An analysis of the relationships between the Inflammatory Bowel Disease Questionnaire and Crohn's Disease Activity Index in Crohn's Disease and measures of utility. Value Health 2007;10:214-20.

55. Luo N, Johnson JA, Shaw JW, et al. Self-reported health status of the general adult U.S. population as assessed by the EQ-5D and Health Utilities Index. Med Care 2005;43:1078-86. 


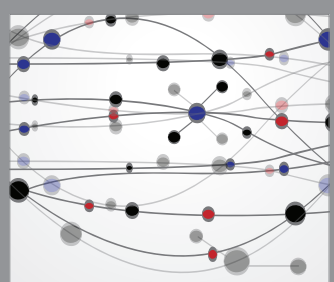

The Scientific World Journal
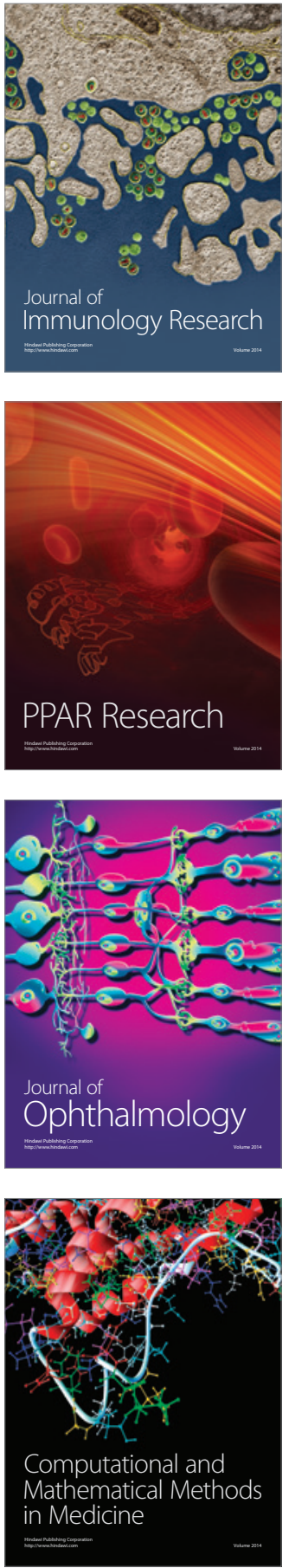

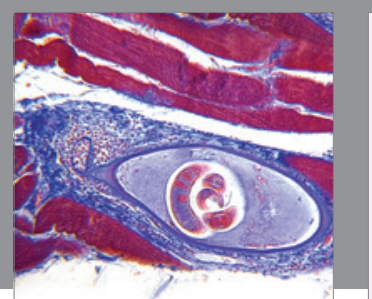

Gastroenterology Research and Practice

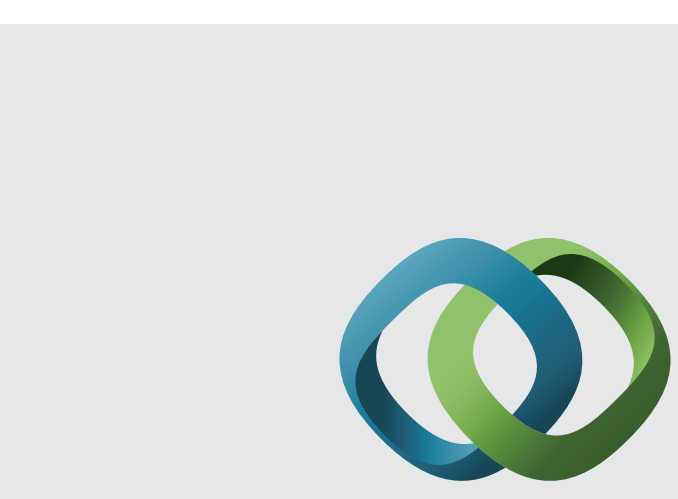

\section{Hindawi}

Submit your manuscripts at

http://www.hindawi.com
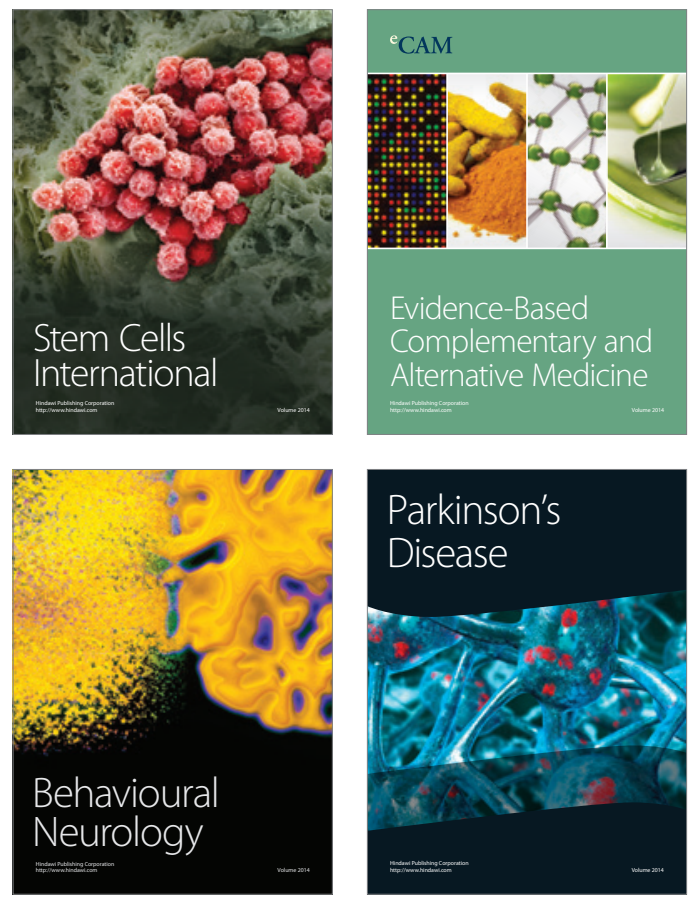
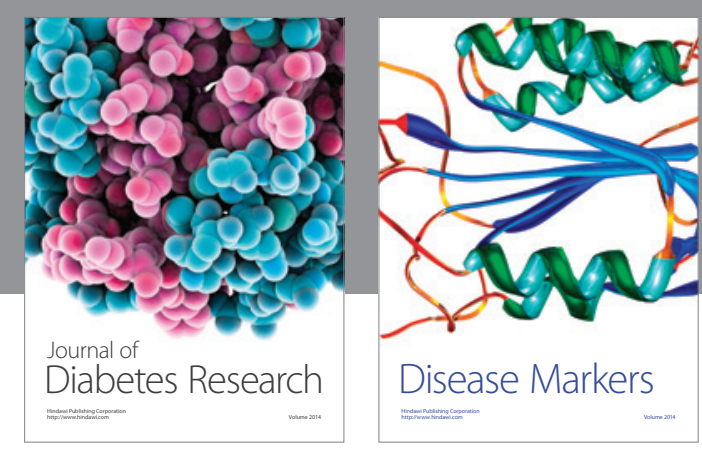

Disease Markers
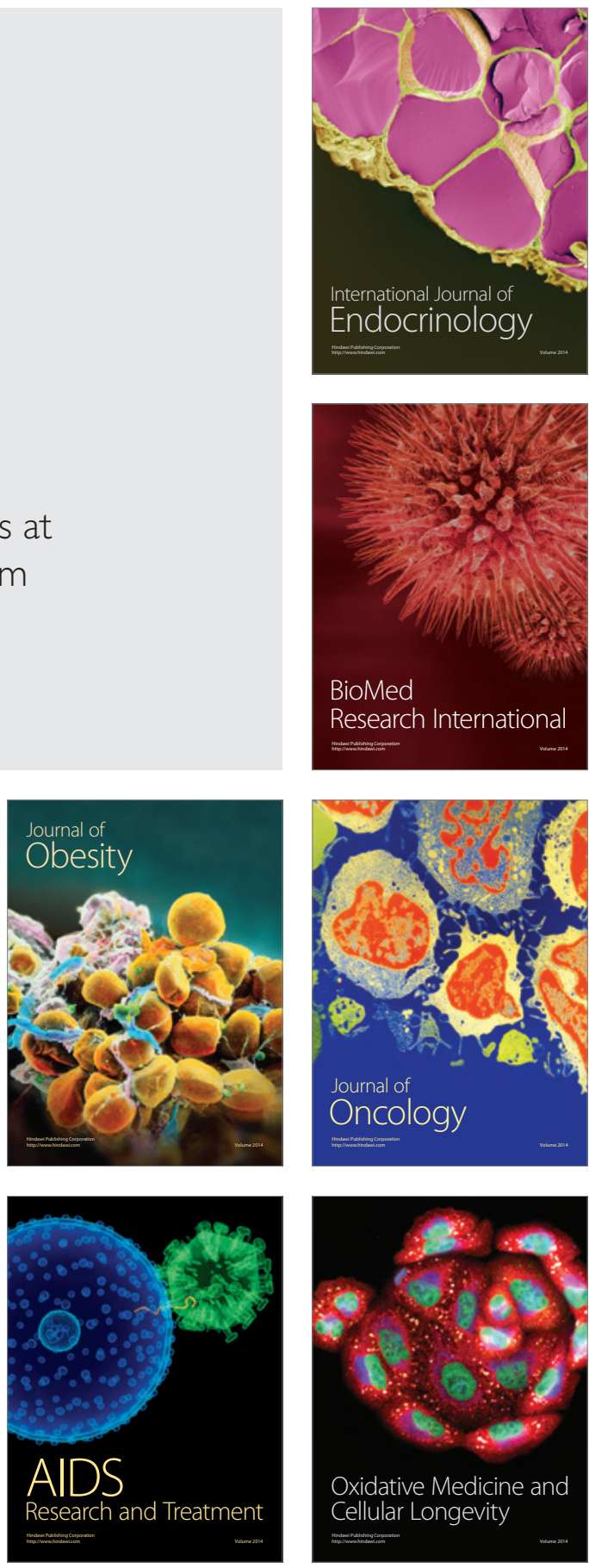